Academy of Management Annual Meeting Proceedings includes abstracts of all papers and symposia presented at the annual conference, plus 6-page abridged versions of the "Best Papers" accepted for inclusion in the program (approximately 10\%). Papers published in the Proceedings are abridged because presenting papers at their full length could preclude subsequent journal publication. Please contact the author(s) directly for the full papers.

\section{Unfolding Collective Social}

\section{Entrepreneurship}

Riccardo Maiolini, Francesco Rullani and Pietro Versari

Published Online: 9 Jul 2018|

https://doi.org/10.5465/AMBPP.2018.14948abstract
P. Free Access
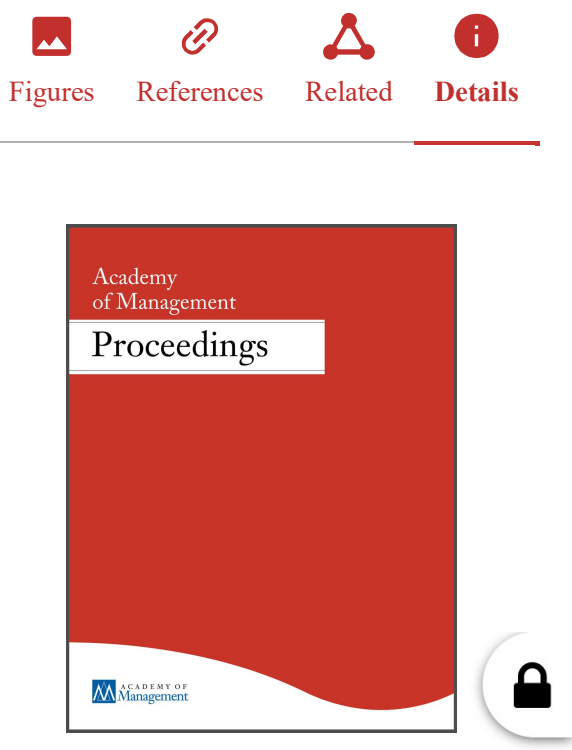

Vol. 2018, No. 1

\section{Permissions}

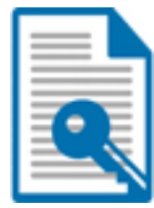

\section{Metrics}

Downloaded 0 times in the past 12 months

\section{History}

Published online 9 July 2018

Published in print 1 August 2018

\section{Information}

Copyright of Academy of Management Proceedings is the property of Academy of Management and its content may 


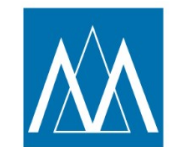

A C A D E M Y O F Management

Academy of Management 555 Pleasantville Road,

Suite N200

Briarcliff Manor, NY

10510-8020, USA

Phone: +1 (914) 326-1800

Fax: +1 (914) 326-1900

Privacy Policy Logo Use (c) 2020 Academy of Management

Powered by Atypon ${ }^{\circledR}$ Literatum 